\title{
Anatomical Study of Various Shapes of Mandibular Coronoid Process in Relation to Gender \&Age .
}

\author{
S.Pradhan ${ }^{1}$, D. P.Bara ${ }^{2}$, S.Patra ${ }^{3}$, S.Nayak ${ }^{4}$, C.Mohapatra ${ }^{5}$ \\ ${ }^{I}$ Senior Resident, Dept of Anatomy, S.C.B Medical College, Cuttack, Odisha, India. \\ ${ }^{2}$ Senior Resident, Dept of Anatomy, S.C.B Medical College, Cuttack, Odisha, India. \\ ${ }^{3}$ Senior Resident, Dept of Anatomy, S.C.B Medical College, Cuttack, Odisha, India. \\ ${ }^{4}$ Senior Resident, Dept of Anatomy, S.C.B Medical College, Cuttack, Odisha, India. \\ ${ }^{5}$ Professor, Dept of Anatomy, S.C.B Medical College, Cuttack, Odisha, India.
}

\begin{abstract}
The Coronoid process is the anterior bony projected part of ramus of mandible giving attachment to two important muscles of mastication. The aim of our study was to observe the gender wise and age wise variation in the shape of coronoid process. The material for this study comprised of 92 (184 sides) dry human mandibles from the osteology bank of Anatomy Department, S.C.B Medical College,Cuttack. The age and sex differentiating criteria were detailed in materials and methods. Three variants of coronoid process were evident with triangular being the highest $46.73 \%$, rounded $35.3 \%$ and hook $17.93 \%$. The incidence of triangular coronoid process predominates in adults and old age of either sex. Rounded was the highest in young and second highest in adult and old of either sex. The hook shaped coronoid process was more in males and older age but absent in younger age group.

This comparative study will be beneficial for the Anthropologists, Forensic scientists and Reconstructive surgeons. As far as our knowledge goes this is the frontier study in the Eastern Indian Population.
\end{abstract}

Keywords: Mandible, Coronoid process, Triangular, Rounded, Hook

\section{Introduction}

The Mandible orthe submaxilla isa ' $U$ ' shaped bone forming the lower jaw, articulating with the temporal bone on either side. It bears a curve shaped body with two rami. Each ramus consists of two processes - coronoid and condylar.

Coronoid process in Greek korone, means "like a crown" which is a beak like projection flattened from side to side at the antero-superior aspect of ramus. In lower animals separate coronoid bones are present which articulate with the splenial, angular, suprangular bones etc to form a common "dentarybone" which is homologous to mandible in humans. There is another coronoid process present in "ulna" and a coronoid fossa in humerus.The largest portion of temporalis muscle is attached to the apex, whole of the medial surface and anterior part of lateral surface. Rest of lateral surface provides attachment to anterior fibres of masseter. These two are important muscles of mastication which show morpho - functional dependence.

Several authors have described the various shapes of coronoid process. According to IssacB ${ }^{1}$, Vipul ${ }^{2}$ and Tanveer $\mathrm{A}^{3}$ process is triangular, hook and rounded whereas Schafer ${ }^{4}$ described it as beak shaped. The shape and size of coronoid process is influenced by dietary habit, genetic constitution, hormonaland mainly by temporalis muscle activity. Coronoid process enlargement maybe seen in some pathological condition likeosteochondroma, exostosis, osteoma and other developmental anomalies. Hernandez-Alfaro $\mathrm{F}^{5}$ noticed a new joint between enlarged coronoid process and zygomatic bone(Jacob's disease) which causes restriction during mouth opening. Though fracture of mandible is common, but still coronoid fracture incidence is rare $(2 \%)$ and requires no treatment unless impingement on the zygomatic arch is present.

Coronoid process is a membranous type of bone which can be removed intra-orally without any functional deficiency and facial disfigurement for reconstruction of orbital floor deformities, alveolar defects, paranasal sinus augmentation, non-union fracture of mandible, osseous defects reconstruction and other repairing procedure in cranio-maxillo facial surgeries. Various morphological features of mandible show changes in reference to age and sex. It acts as an anthropological marker for detection of races. The present study was undertaken to determine the variations in shape of coronoid process in relation to age and sex and compare it with other population studies. 


\section{Materials and methods}

The present study was conducted on ninety-two dry human mandibles (48 male and 44 female) from the osteology bank of anatomy department of S.C.B medical college, Cuttack. Determination of sex was done according to following criteria's:

MaleFemale

1. Gonial eversion -

2. Chin - square

marked rounded

3. Muscular impression - more prominent slight

less prominent

Bones collected were then grouped into three categories

I - Young age $\rightarrow$ third molar not erupted, MF towards base

II - Adult $\rightarrow$ third molar erupted, MF in middle

III - Old age groups $\rightarrow$ resorption of alveolar margin, MF towards upper margin.

$$
\mathrm{MF}=\text { mental foramen }
$$

The study was done in different times of study period and the mandibles were examined for the variations in shape of coronoid process. Any mandible broken or dysmorphed were excluded from the study.

\section{Observations and Results:}

The shape of coronoid was classified into 3 types:

1. Triangular $\rightarrow$ tip pointing directly upwards

2. Rounded $\rightarrow$ tip rounded

3. Hook $\rightarrow$ tip pointing backwards

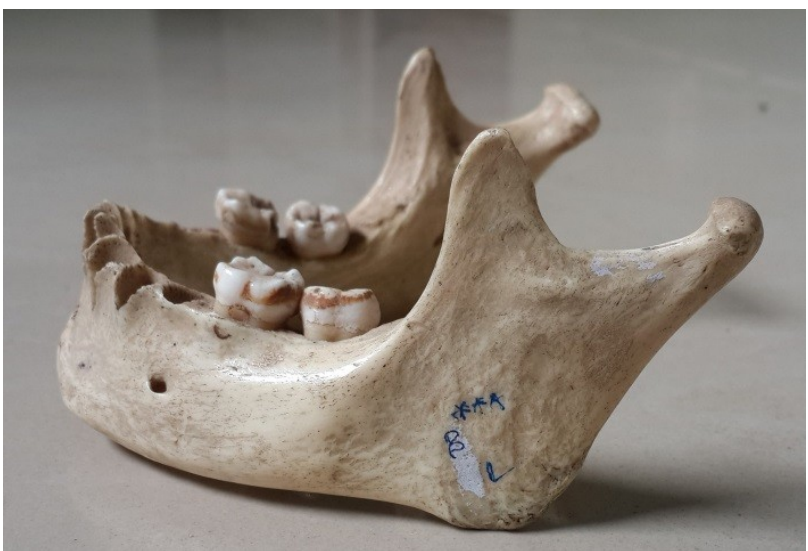

Fig 1: Triangular coronoid Process

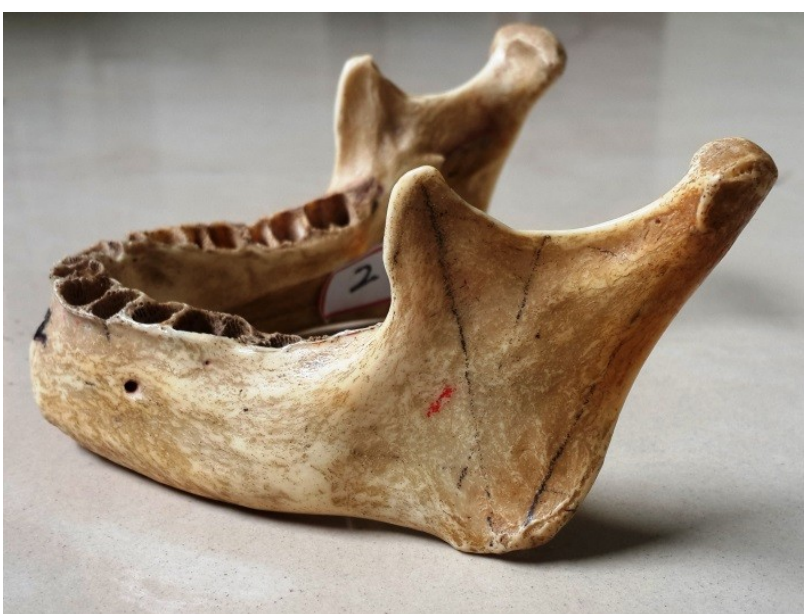

Fig 2 : Rounded Coronoid Process 


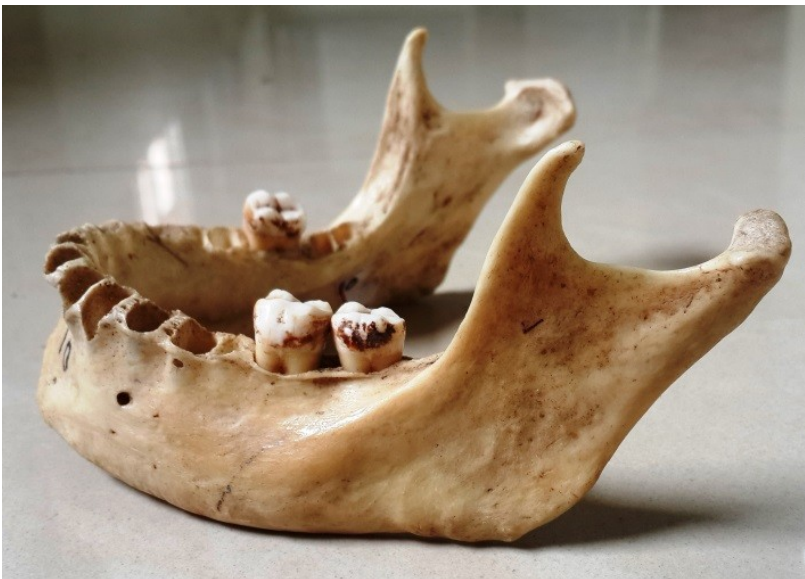

Fig 3: Hook shaped Coronoid Process

Table 1: Distribution of various shapes of coronoid process

\begin{tabular}{|l|l|l|l|l|l|}
\hline \multirow{2}{*}{ Types } & \multirow{2}{*}{$\begin{array}{l}\text { Shapes of coronoid } \\
\text { process }\end{array}$} & $\%$ & Bilateral & \multicolumn{2}{|l|}{ Unilateral } \\
\cline { 5 - 7 } & Triangular & $86(46.73 \%)$ & 72 & 6 & 8 \\
\hline 1 & Rounded & $65(35.3 \%)$ & 54 & 4 & 7 \\
\hline 3 & Hook & $33(17.93 \%)$ & 24 & 7 & 2 \\
\hline
\end{tabular}

\section{DISTRIBUTION OF VARIOUS SHAPES OF CORONOID PROCESS}

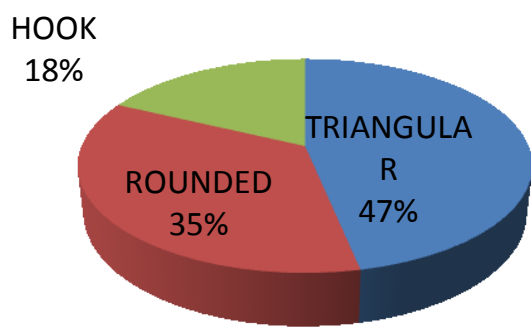

Fig 4 : Percentage of various shapes of coronoid process

Out of total 184 sides (92 mandibles) studied, incidence of triangular coronoid process was found to be maximum i.e. 86 sides (46.73\%). In 32 mandiblesit was found bilaterally and in 14 mandibles it was present unilaterally. Coronoid process with rounded tip was found in 35.3\%i.e 65 sides .In 27 mandible it was present bilaterally and in 11 mandibles it was unilaterally. Incidence of hook shape was least 17.93\%i.e 33 sides, 24 (12 mandible) bilateral and 9 unilateral in presentation.

Table -2: Genderwise distribution and incidence of shapes of coronoid process.

\begin{tabular}{|l|l|l|l|}
\hline Gender & Triangular & Rounded & Hook \\
\hline $\begin{array}{l}\text { Male } \\
\mathrm{N}=48\end{array}$ & $44(45.83 \%)$ & $31(32.29 \%)$ & $21(21.87 \%)$ \\
\hline $\begin{array}{l}\text { Female } \\
\mathrm{N}=44\end{array}$ & $42(47.72 \%)$ & $34(38.63 \%)$ & $12(13.63 \%)$ \\
\hline
\end{tabular}

$\mathrm{N}=$ number of mandible 


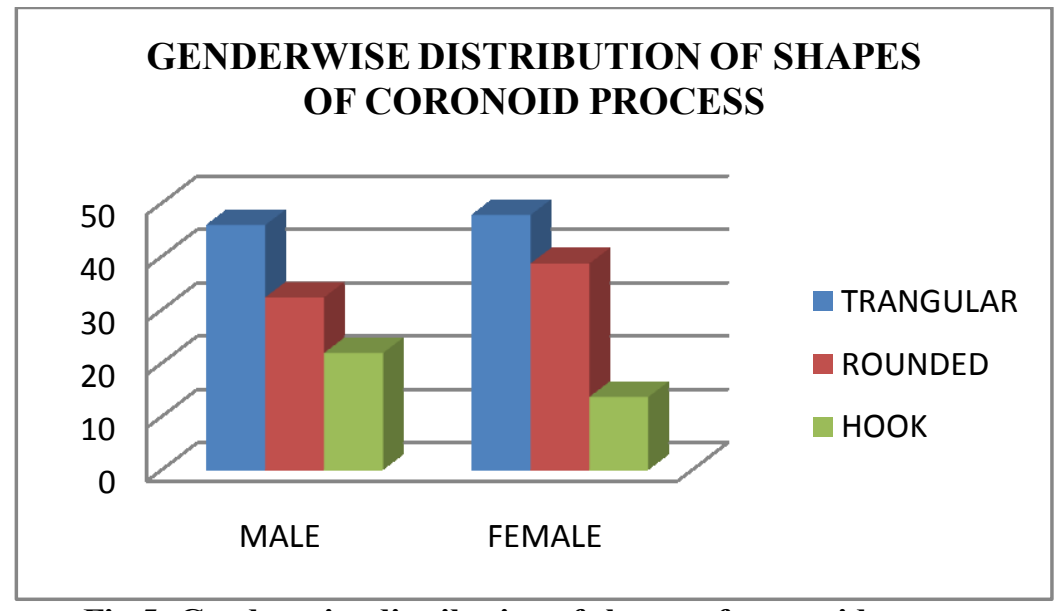

Fig 5: Gender wise distribution of shapes of coronoid process

Table -2shows gender-wise distribution of different types.In the present study we found that 48 mandible belonging to males, triangular shaped coronoid process was found in 44 sides $(45.83 \%)$, round shaped in 31 sides $(32.29 \%)$ and hook shaped in 21 sides $(21.87 \%)$. In females coronoid process was triangular shaped in $47.72 \%$, rounded in $38.63 \%$ and hook shaped in $13.63 \%$.

Table: 3 Age wise distribution of the shapes of coronoid process.

\begin{tabular}{|l|l|l|l|l|}
\hline Age groups & $\mathrm{N}$ & Triangular & Rounded & Hook \\
\hline Young & $11(22$ sides $)$ & $8(36.36 \%)$ & $14(63.63 \%)$ & - \\
\hline Adult & $51(102$ sides $)$ & $48(47.05 \%)$ & $35(34.31 \%)$ & $19(18.62 \%)$ \\
\hline Old & $30(60$ sides $)$ & $30(50 \%)$ & $16(26.66 \%)$ & $14(23.33 \%)$ \\
\hline
\end{tabular}

$\mathrm{N}=$ number of mandible

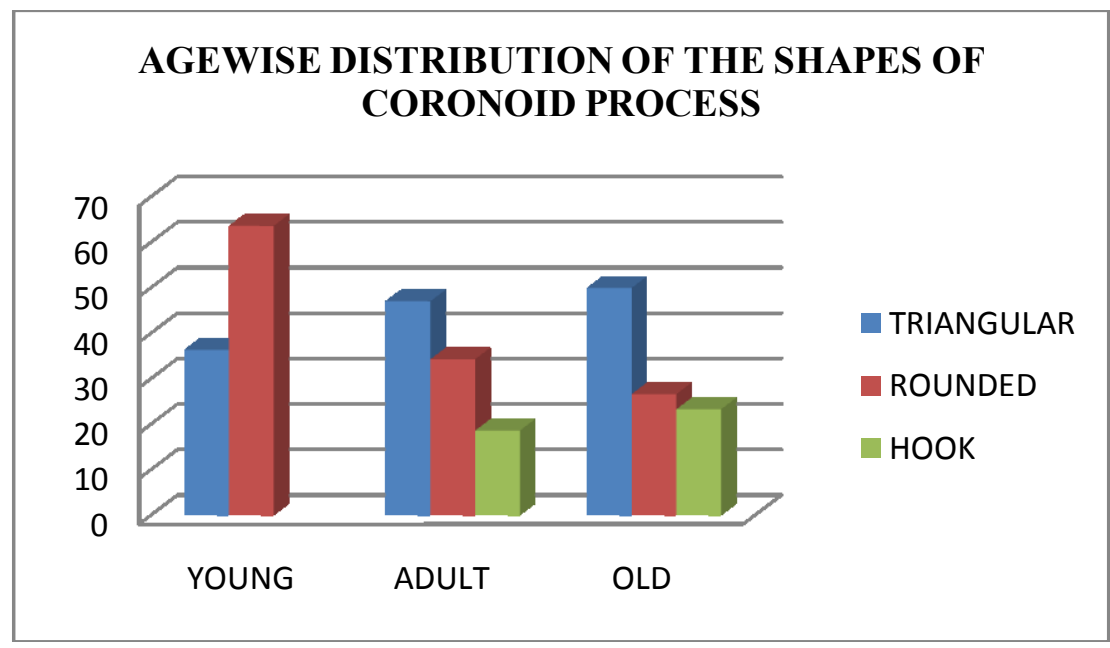

Fig 6: Age wise prevalence of types of coronoid process

In our study of 92 mandibles, 11 mandibles were of young age group, 51 of adults, and 30 of old age groups. It was found that in young age group coronoid process was round in $63.63 \%$ and rest $36.36 \%$ were triangular but no hooks.In adult age groups 48(47.05\%) sides were triangular, $35(34.31 \%)$ rounded and 19 $(18.62 \%)$ hook. In old age group $50 \%$ were triangular, $26.66 \%$ were rounded and $23.33 \%$ were hook shaped. 
Table 4: Comparison of various studies of coronoid shapes in different regions of India

\begin{tabular}{|l|l|l|l|}
\hline \multirow{2}{*}{ Authors } & \multicolumn{2}{|l|}{ Types of coronoid process } & Hook \\
\cline { 2 - 4 } & Triangular & Rounded & $30 \%$ \\
\hline $\begin{array}{l}\text { Tanveer A(2011) } \\
\text { South India }\end{array}$ & $67 \%$ & $3 \%$ & $21.25 \%$ \\
\hline $\begin{array}{l}\text { Vipul et al (2011) } \\
\text { Western India }\end{array}$ & $54.17 \%$ & $24.58 \%$ & $22 \%$ \\
\hline $\begin{array}{l}\text { Dr Smita Tapas(2014) } \\
\text { North India }\end{array}$ & $60 \%$ & $18 \%$ & $17.93 \%$ \\
\hline $\begin{array}{l}\text { Present study (2014) } \\
\text { Eastern India }\end{array}$ & $46.73 \%$ & $35.3 \%$ & \\
\hline
\end{tabular}

\section{Discussion}

The coronoid process develops as a discrete entity within the mass of the temporalis muscle anlage, subsequently it unites with the main portion of mandibular ramus at approximately eight weeks of age ${ }^{6}$. Standard textbooks describe coronoid process to be flat and triangular. However in many reported journalsrounded and hook shaped coronoid process was also illustrated.

The morphological variations of shape of coronoid process in our study suggest that triangular shape was the most common presentation unilaterally and bilaterally in $46.73 \%$ and hook shape being the least with $17.93 \%$ only. The highest incidence of triangular shape corroborates with findings Tanveer A et al, Vipul et al and Isaac B et al whereas it contradicts with the study done by Sinan Bakirci et $\mathrm{al}^{7}$ in Turkish population and SM AkramHossain ${ }^{8}$ in Bangladeshi population where hook shaped was the highest. Nirmale et $\mathrm{al}^{9}$ studied 84 mandible and found that after triangular, hook shape was the next common presentation.

According to table 2 and graph -2, in both sexes incidence of triangular shaped coronoid process was highest but in males the hook shape was more i.e. $21.87 \%$ whereas it was $13.63 \%$ in females. Round shaped coronoid process was more in females $(38.63 \%)$ than in males(32.29\%). This difference in both the sexes might be due to different chewing habits, hormones, attachments and direction of pull of temporalis muscle. These findings were found to be similar to that of $\mathrm{R}$ Sudha et $\mathrm{al}^{10}$. But Vipul noted hook shape to be equal in both sexes. Vikas. C.Desai ${ }^{11}$ found rounded type more in male which contradicts our study.

Studying the table 3 \& graph 3 rounded coronoid process was found maximum in the young age group with no incidence of hook shape whereas in the adults and old age triangular shape was the highest and hook was the least. Probably the difference in the shape was dueto traction by the Temporalis muscle which changes the shape from rounded to triangular as the age advances. Not many authors have reported the age wise distribution. $\mathrm{R}$ Sudha et al have studied 15 edentulous bones and found $53.3 \%$ to be hook which varies from our result. Finnegan, M $1974^{12}$ and Berry $1975^{13}$ mentioned that these differences can be due to role played by genes.

On comparison of various studies of coronoid shapes in different regions of India, it was found that triangular type predominates in all the studies with hook being the second in North and South India. Rounded type of coronoid process was the second most common in the Western part of India which closely corroborates with our study done in Eastern Indian population.

As mandible is one of the strongest bone present in the body its remains can be used as non metric variants for anthropological and forensic sciences. Coronoid process is suitable for donor graft site for orbital floor reconstruction. Mintz et $\mathrm{al}^{14} 1998$. Clauseret $\mathrm{al}{ }^{15} 1995$ reported the use of temporal myofascial flap both as a single and as composite flap with cranial bone, as the arteries supplying the coronoid process also supply the muscles attached to it.

\section{Conclusion}

Our study of anatomical variation of shapes of coronoid process suggest that triangular shape is the most common presentation in both males and females followed by round and then hook shaped. With increase in age the shape of coronoid process gradually changes from round to triangular. The prevalence of hooked coronoid process is more in males and older age but absent in younger age .

The data provided by the present study will help the dental and maxillo-facial surgeons in planning graft implants and reconstructive surgeries. More studies involving larger sample size and other group of population is desirable for better correlation of age and sex change in shape of coronoid process. 


\section{References}

[1] Isaac, B.; Holla S.J. Variations in the Shape of the Coronoid Processin the Adult Human Mandible.Journal Anat. Soc India.2001;50(2):137-139.

[2] Vipul P Prajapati.,OjaswiniMalukar,S K Nagar. Variations in themorphological appearance of the coronoid process of humanmandible. National Journal of Medical Research. 2011;1(2).

[3] TanveerAhamed Khan H. S., J.H. Sharieff. Observation onMorphological Features of Human Mandibles in 200 South IndianSubjects. Anatomica Karnataka. 2011;5(1):44-49.

[4] Schafer E. A. and Thane G. D. : Quain's Elements ofAnatomy. In : The bones of the head. 10th Edn; (Longmans,green \& Co. London pp. 60,1890$)$

[5] Hernandez-Alfaro F, Escuder O, Marco V. Joint formation between an osteochondroma of the coronoid process and the zygomatic arch (Jacob disease): report of case and review of literature. J Oral Maxillofac Surg. 2000;58:227-232.

[6] Meropi N. Spyropoulos.The morphogenetic relationship of the temporal muscle to the coronoid process in human embryos and fetuses. American Journal of Anatomy Volume 150, Issue 3, pages 395-409, November 1977.

[7] SinanBakirci ,Ilknur Ari, Ilker Mustafa Kafa.Morphometric characteristics and typology of coronoid process of the mandible.Acta Medica Meriterranea, 2000,29:683-686

[8] SM AkramHossain, SM Moshadeq Hossain, Fakhrul Amin Mohammad Hasanul Banna, Variation in the shape of the coronoid process in the adult human mandible, Bangladesh journal of anatomy ,July 2011, Vol.9 (2) 75-78

[9] Nirmale VK, Mane UW, Sukre SB, Diwan CV. Morphological Features of Human Mandible. Int J of RecentTrends in Sci Technol. $2012 ; 3$ (2): 38-43.

[10] R Sudha, ShantaChandrasekaran, N. Aruna, Study of morphological variations in the shapes of coronoid process of mandible in South Indian population, IJCRR, May 2013 Vol 5(10): 84-90

[11] Vikas C Desai, Desai SD, Hussain N Aruna, Morphological study of mandible, Journal of pharmaceutical sciences and research, Vol 6(4), 2014,175-177

[12] Finnegan,M.(1974).Discrete non-metric variation of the post-cranial skeleton in man. Abstract.American Journal of Physical Anthropology 40,135-136.

[13] Berry, A. C. (1975) : Factors affecting the incidence of nonmetricalskeletal variants. Journal of Anatomy 120: $519-535$

[14] Mintz S.M., Ettinger, A., Schmakel,T. and Gleason M. J.(1998) Contralateral coronoid process bone grafts for orbitalfloor reconstruction : an anatomic and clinical study. Journalof Oral Maxillofacial Surgery 56 (10): 1140-1145.

[15] Clauser L., Curioni, C. and Spanio, S. (1995): The use of thetemporalis muscle flap in facial and craniofacialreconstructive surgery. A review of 182 cases.Journal ofCraniomaxillofacial Surgery 23 (4): 203-214 